Pacific Journal of Mathematic 


\section{A NOTE ON THE COMPUTATION OF ALDER'S POLYNOMIALS}

\section{N. SingH}

In two recent papers $[2,3]$ I deduced and used the general transformation

$$
\begin{aligned}
1 & +\sum_{s=1}^{\infty}(-1)^{s} k^{M s} x^{\frac{1}{2} s\{(2 M+1) s-1\}}\left(1-k x^{2 s}\right) \frac{(k x ; s-1)}{(x ; s)} \\
& =\prod_{n=1}^{\infty}\left(1-k x^{n}\right) \sum_{t=0}^{\infty} \frac{k^{\prime} G_{M, t}(x)}{(x ; t)}, \quad(M=2,3, \cdots)
\end{aligned}
$$

to prove certain generalized identities of the type

$$
\begin{aligned}
& \prod_{n=1}^{\infty} \frac{\left(1-x^{(2 M+1) n-s}\right)\left(1-x^{(2 M+1) n-(2 M+1-s)}\right)\left(1-x^{(2 M+1) n}\right)}{\left(1-x^{n}\right)} \\
& \quad=\sum_{t=0}^{\infty} \frac{A_{s}(x, t) G_{M, t}(x)}{(x ; t)}
\end{aligned}
$$

where $A_{s}(x, t)$ and $G_{M, t}(x)$ are polynomials. For $s=M$ and $s=1$ respectively in (2), we get Alder's generalizations of the well-known Rogers-Ramanujan identities

$$
\prod_{n=1}^{\infty} \frac{\left(1-x^{5 n-2}\right)\left(1-x^{5 n-3}\right)\left(1-x^{5 n}\right)}{\left(1-x^{n}\right)}=\sum_{t=0}^{\infty} \frac{x^{t^{2}}}{(x ; t)}
$$

and

$$
\prod_{n=1}^{\infty} \frac{\left(1-x^{5 n-1}\right)\left(1-x^{5 n-4}\right)\left(1-x^{5 n}\right)}{\left(1-x^{n}\right)}=\sum_{t=0}^{\infty} \frac{x^{t(t+1)}}{(x ; t)}
$$

in the form [1]

$$
\prod_{n=1}^{\infty} \frac{\left(1-x^{(2 M+1) n-M}\right)\left(1-x^{(2 M+1) n-M-1}\right)\left(1-x^{(2 M+1) n}\right)}{\left(1-x^{n}\right)}=\sum_{t=0}^{\infty} \frac{G_{M, t}(x)}{(x ; t)}
$$

and

$$
\prod_{n=1}^{\infty} \frac{\left(1-x^{(2 M+1) n-1}\right)\left(1-x^{(2 M+1) n-2 M}\right)\left(1-x^{(2 M+1) n}\right)}{\left(1-x^{n}\right)}=\sum_{t=0}^{\infty} \frac{x^{t} G_{M, t}(x)}{(x ; t)} .
$$

For the Alder polynomials $G_{M I, \ell}(x)$ in (1), I gave the general form

$$
G_{M, t}(x)=x^{t^{2}} \sum_{t_{1}=0}^{[M-1} \frac{\left(x^{M-2} t\right]}{\left(x ; t_{1}\right)} \frac{\left(x^{t-2 t_{1}+1} ; 2 t_{1}\right) x^{-2 t_{1}\left(t-t_{1}\right)}}{\prod_{n=2}^{M-2}} T_{n, M}
$$

Received June 3, 1958. 
where

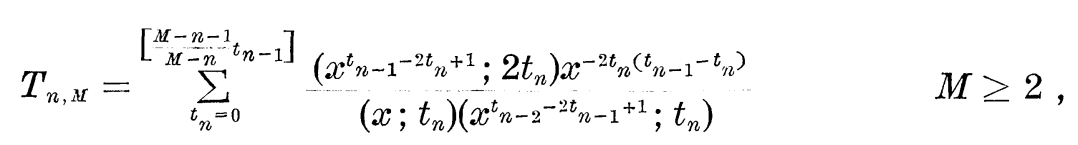

[a] denoting the integral part of $a$.

Alder in his paper [1] states that the polynomials $G_{M, t}(x)$ do not seem to possess any striking properties, even for small values of $M$ and $t$. In the present note, using a simple recurrence relation, I prove beside other results the interesting property that

$$
G_{M, t}(x)=x^{t}, \quad t \leq(M-1) .
$$

The form (3) is not very suitable for the actual computation of the polynomials $G_{M, l}(x)$ for particular values of $M$ and $t$ since certain factor have to be cancelled each time. Therefore, moving into the following series the factor $\left(x^{t-2 t_{1}+1} ; t_{1}\right)$ from the first series and the factor $\left(x^{t} n_{-1}^{-2 t_{n}+1} ; t_{n}\right)$ from each of the $T_{n, M}$ series in (3), we put $G_{M, t}(x)$ in the form

$$
G_{M, t}(x)=x^{t^{2}} \sum_{t_{1}=0}^{\left[\begin{array}{c}
M-2 \\
M-1
\end{array}\right]} \frac{\left(x^{t-t_{1}+1} ; t_{1}\right) x^{-2 t_{1}\left(t-t_{1}\right)}}{\left(x ; t_{1}\right)} \prod_{n=2}^{M-1} \bar{T}_{n, M} .
$$

where

$$
\begin{aligned}
\bar{T}_{n, M}= & \sum_{t_{n}=0}^{\left[\stackrel{M-n-1}{M-n} t_{n-1}\right]} \frac{\left(x^{t_{n-1}-t_{n}+1} ; t_{n}\right) a^{-2 t_{n}\left(t_{n-1}-t_{n}\right)}}{\left(x ; t_{n}\right)} \\
& \times\left(x^{t_{n-2}-2 t_{n-1}+t_{n}+1} ; t_{n-1}-t_{n}\right) .
\end{aligned}
$$

Now if we put

$$
g_{M, t}(N, x)=\prod_{n=1}^{M-1} \bar{T}_{n, M} \quad\left(\text { where } t_{-1} \equiv N\right)
$$

then, since

$$
\begin{aligned}
g_{M, t}(N, x)= & \sum_{t_{1}=0}^{\left[\begin{array}{c}
M=-2 \\
M=-1
\end{array}\right]} \frac{\left(x^{t-t_{1}+1} ; t_{1}\right)\left(x^{N-2 t+t_{1}+1} ; t-t_{1}\right)}{\left(x ; t_{1}\right)} \\
& \times x^{-2 t_{1}\left(t-t_{1}\right)} g_{M-1, t_{1}}(t, x),
\end{aligned}
$$

it is easily seen by induction that for $t \leq M-1$, we have

$$
g_{M+1, t}(N, x)-g_{M, t}(N, x)=0
$$

because

$$
\left[\begin{array}{l}
M-2 \\
M-1
\end{array}\right]+1>\left[\begin{array}{c}
M-1 \\
M
\end{array}\right] \quad t \leq M-1
$$


From (4) we have

$$
\begin{gathered}
G_{M+1, t}(x)-G_{M, t}(x) \\
=x^{t^{2}} \sum_{t=0}^{\left[\begin{array}{c}
M-2 \\
M-1
\end{array}\right]} \frac{\left(x^{t-t_{1}+1} ; t_{1}\right) x^{-2 t_{1}\left(t-t_{1}\right)}}{\left(x ; t_{1}\right)}\left\{g_{M, t_{1}}(t, x)-g_{M-1, t_{1}}(t, x)\right\} \\
+\sum_{t_{1}=\left[\begin{array}{l}
M-2 \\
M-1
\end{array}\right]+1}^{\left[\frac{M-1}{M} t\right]} \frac{\left(x^{t-t_{1}+1} ; t_{1}\right) x^{-2 t_{1}\left(t-t_{1}\right)}}{\left(x ; t_{1}\right)} g_{M, t_{1}}(t, x) .
\end{gathered}
$$

Hence from (8) and (9) it follows that, for $t \leq M-1$,

$$
G_{M, t}(x)=G_{M+1, t}(x)
$$

that is,

$$
G_{M, t}(x)=G_{M+1, t}(x)=\cdots=G_{\infty, t}(x), \quad t \leq M-1 .
$$

Now, for $k=1$ and $M \rightarrow \infty$, (1) gives

$$
\frac{1}{\prod_{n=1}^{\infty}\left(1-x^{n}\right)}=\sum_{t=0}^{\infty} \frac{G_{\infty, t}(x)}{(x ; t)}
$$

whence $G_{\infty, t}(x)=x^{t}$, so that we finally get

$$
G_{M, t}(x)=x^{t} \quad t \leq M-1 .
$$

(10) can be further used for the computation of polynomials $G_{M, t}(x)$ as follows.

We first find the general form for $G_{M, M}(x)$.

From (10) we have

$$
G_{M+1, M}(x)-G_{M, M}(x)=x_{M} x^{-2(M-1)} g_{M, M-1}(M, x),
$$

where $x_{n} \equiv\left(1-x^{n}\right) /(1-x)$ for all $n$.

From (7) we find

$$
g_{M, M-1}(M, x)=(x ; M-1) x^{-(M-1)(M-2)} .
$$

Using (13) in (12) we get

$$
G_{M, M}(x)=x^{M}\left\{1-\left(x^{2} ; M-1\right)\right\}
$$

since $G_{M+1, M}(x)=x^{M}$. Thus, for example,

$$
G_{5,5}(x)=x^{7}+x^{8}+x^{9}-x^{11}-2 x^{12}-x^{13}+x^{15}+x^{16}+x^{17}-x^{19} .
$$

More generally, taking $t=M+r$ in (7), since 


$$
\left[\frac{M^{2}+(r-2) M-2 r}{M-1}\right]=M+r-2 \quad r \leq M-2,
$$

and

$$
\left[\frac{M^{2}+(r-1) M-r}{M}\right]=M+r-2 \quad 0<r \leq M,
$$

we easily get

$$
\begin{gathered}
g_{M+1, M+r}(N, x)-g_{M, M+r}(N, x) \\
=\prod_{n=1}^{r} \bar{T}_{n, M}\left\{g_{M-r+1, M-r}\left(t_{r-1}, x\right)-g_{M-r, M-r}\left(t_{r-1}, x\right)\right\} \quad 0>r \leq M-2,
\end{gathered}
$$

where, in $\bar{T}_{n, M}, t=M+r$ and $t_{r}=M-r$. Thus for $t \leq 2 M-2(t \neq M)$ the second sum on the right of (10) does not exist and we may successively establish the general form of the polynomials $G_{M, t}(x)$ for $M<t \leq$ $2(M-1)$. We thus find that

$$
G_{M+1, M+1}(x)-G_{M, M+1}(x)=x^{M+3}\left(x^{3} ; M-1\right) x_{2} \quad M \geq 3,
$$

so that, using (14), we get

$$
G_{M, M+1}(x)=x^{M+1}\left\{1-\left(x^{3} ; M-1\right)\left(1+x^{3}\right)\right\} \quad M \geq 3 .
$$

Similarly

$$
\begin{array}{ll}
G_{M, M+2}(x)=x^{M+2}\left\{1-\left(x^{4} ; M-1\right)\left(1+x^{4} \cdot x_{2}\right)\right\} & M \geq 4, \\
G_{M, M+3}(x)=x^{M+3}\left\{1-\left(x^{5} ; M-1\right)\left(1+x^{5} \cdot x_{3}\right)\right\} & M \geq 5,
\end{array}
$$

The above values of the polynomials $G_{M, t}(x)$ suggest that probably,

$$
\begin{gathered}
G_{M, t}(x)=x^{t}\left\{1-\left(x^{t-M+2} ; M-1\right)\left(1+x^{t-M+2} \cdot x_{t-M}\right)\right\}, \\
t \leq 2(M-1) .
\end{gathered}
$$

for

But I have not been able to verify the truth of this conjecture directly.

However, I intend to investigate these interesting polynomials more thoroughly in a future communication.

I am grateful to Dr. R. P. Agarwal for his kind help in the preparation of this note. 


\section{REFERENCES}

1. H. L. Alder Generalizations of the Rogers-Ramanujan identities, Pacific J. Math. 4 (1954), 161-168.

2. V. N. Singh, Certain generalized hypergeometric identities of the Rogers-Ramanujan type, Pacific J. Math. 7 (1957), 1011-1014.

3. - Certain generalized hypergeometric identities of the Rogers-Ramanujan type (II), Pacific J. Math. 7 (1957), 1691-99.

LUCKNOW UNIVERSITY 



\section{PACIFIC JOURNAL OF MATHEMATICS}

\section{EDITORS}

\section{David Gilbarg}

Stanford University

Stanford, California

R. A. Beaumont

University of Washington

Seattle 5 , Washington
A. L. Whiteman

University of Southern California

Los Angeles 7, California

L. J. PAIGE

University of California

Los Angeles 24, California

\section{ASSOCIATE EDITORS}
E. F. BECKENBACH
C. E. BURGESS
E. HEWITT
A. HORN

\author{
V. GANAPATHY IYER \\ R. D. JAMES \\ M. S. KNEBELMAN \\ L. NACHBIN
}
I. NIVEN
E. G. STRAUS
T. G. OSTROM
H. L. ROYDEN
G. SZEKERES
M. M. SCHIFFER
F. WOLF
K. YOSIDA

\section{SUPPORTING INSTITUTIONS}

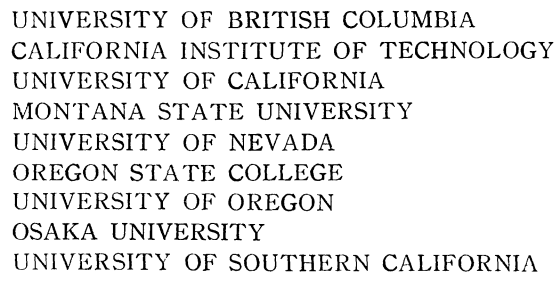

UNIVERSITY OF BRITISH COLUMBIA CALIFORNIA INSTITUTE OF TECHNOLOGY UNIVERSITY OF CALIFORNIA MONTANA STATE UNIVERSITY UNIVERSITY OF NEVADA OREGON STATE COLLEGE UNIVERSITY OF OREGON OSAKA UNIVERSITY UNIVERSITY OF SOUTHERN CALIFORNIA

STANFORD UNIVERSITY

UNIVERSITY OF TOKYO

UNIVERSITY OF UTAH

WASHINGTON STATE COLLEGE

UNIVERSITY OF WASHINGTON

AMERICAN MATHEMATICAL SOCIETY CALIFORNIA RESEARCH CORPORATION HUGHES AIRCRAFT COMPANY SPACE TECHNOLOGY LABORATORIES

Printed in Japan by Kokusai Bunken Insatsusha (International Academic Printing Co., Ltd.), Tokyo, Japan 


\section{Pacific Journal of Mathematics}

\section{Vol. 9, No. 1 \\ May, 1959}

Julius Rubin Blum and Murray Rosenblatt, On the structure of infinitely

divisible distributions . ............................. 1

Robert Geroge Buschman, Asymptotic expressions for

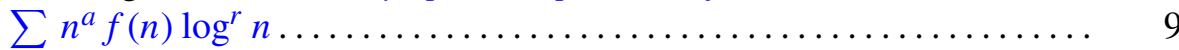

Eckford Cohen, A class of residue systems $(\bmod r)$ and related arithmetical

functions. I. A generalization of Möbius inversion .............. 13

Paul F. Conrad, Non-abelian ordered groups ................... 25

Richard Henry Crowell, On the van Kampen theorem............... 43

Irving Leonard Glicksberg, Convolution semigroups of measures ........ 51

Seymour Goldberg, Linear operators and their conjugates ............ 69

Olof Hanner, Mean play of sums of positional games .............. 81

Erhard Heinz, On one-to-one harmonic mappings ................ 101

John Rolfe Isbell, On finite-dimensional uniform spaces . . ........... 107

Erwin Kreyszig and John Todd, On the radius of univalence of the function

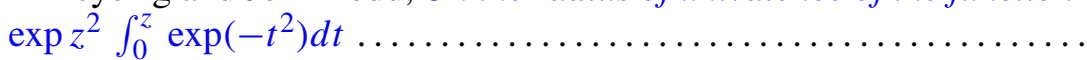

Roger Conant Lyndon, An interpolation theorem in the predicate

calculus......................................... 129

Roger Conant Lyndon, Properties preserved under homomorphism ........ 143

Roger Conant Lyndon, Properties preserved in subdirect products ....... 155

Robert Osserman, A lemma on analytic curves ................ 165

R. S. Phillips, On a theorem due to Sz.-Nagy..................... 169

Richard Scott Pierce, A generalization of atomic Boolean algebras ....... 175

J. B. Roberts, Analytic continuation of meromorphic functions in valued fields................................. 183

Walter Rudin, Idempotent measures on Abelian groups ................ 195

M. Schiffer, Fredholm eigen values of multiply-connected domains ........ 211

V. N. Singh, A note on the computation of Alder's polynomials ......... 271

Maurice Sion, On integration of 1-forms ...................... 277

Elbert A. Walker, Subdirect sums and infinite Abelian groups........... 287

John W. Woll, Homogeneous stochastic processes . .................. 293 